\title{
A needs assessment for simulation-based training of emergency medical providers in Nebraska, USA
}

Nizar K. Wehbi ${ }^{1 *}$ D, Rajvi Wani ${ }^{1}$, Yangyuna Yang ${ }^{1}$, Fernando Wilson', Sharon Medcalf², Brian Monaghan³, Jennifer Adams $^{3}$ and Paul Paulman ${ }^{3}$

\begin{abstract}
Background: Training emergency medical services (EMS) workforce is challenging in rural and remote settings. Moreover, critical access hospitals (CAHs) struggle to ensure continuing medical education for their emergency department (ED) staff. This project collected information from EMS and ED providers across Nebraska to identify gaps in their skills, knowledge, and abilities and thus inform curriculum development for the mobile simulationbased training program.
\end{abstract}

Methods: The needs assessment used a three-step process: (1) four facilitated focus group sessions were conducted in distinct geographical locations across Nebraska to identify participants' perceived training gaps; (2) based on the findings from the focus group, a needs assessment survey was constructed and sent to all EMS and ED staff in Nebraska; and (3) 1395 surveys were completed and analyzed.

Results: Thematic areas of training gaps included cardiopulmonary conditions, diabetes management, mass casualty incidents $(\mathrm{MCl})$, maternal health and child delivery, patient assessment, pediatric care (PC), and respiratory emergency care. Gaps in non-clinical skills were related to crisis management such as maintaining effective teamwork. Participants frequently identified cardiopulmonary care, PC, and $\mathrm{MCl}$ as highly needed trainings. Other needs included life support-related retaining courses, sessions informing protocol updates, the availability of retraining tailored for rural areas, substance use-related emergencies, and farming-related injuries.

Conclusion: EMS and ED staff identified several skill gaps and training needs in the provision of emergency services in rural communities. These results allow for the development of customized training curricula and, with the help of an on-site simulation-based program, can identify gaps in health professionals' skills, knowledge, and abilities and thus help them respond to acute healthcare needs of rural communities.

Keywords: Emergency medical services, Emergency medical technicians, Needs assessment, Simulation training, Rural health

\footnotetext{
* Correspondence: nizar.wehbi@unmc.edu

${ }^{1}$ Department of Health Services Research and Administration, College of

Public Health, University of Nebraska Medical Center, 984350 Nebraska

Medical Center, Omaha, NE 68198-4350, USA

Full list of author information is available at the end of the article
}

(c) The Author(s). 2018 Open Access This article is distributed under the terms of the Creative Commons Attribution 4.0 International License (http://creativecommons.org/licenses/by/4.0/), which permits unrestricted use, distribution, and reproduction in any medium, provided you give appropriate credit to the original author(s) and the source, provide a link to the Creative Commons license, and indicate if changes were made. The Creative Commons Public Domain Dedication waiver (http://creativecommons.org/publicdomain/zero/1.0/) applies to the data made available in this article, unless otherwise stated. 


\section{Background}

One third of rural counties in Nebraska are either partially or wholly designated as a primary care health professional shortage area which are geographic areas or populations with too few primary care providers [1]. The poor access to care in rural communities highlights the importance of having an effective acute care infrastructure, consisting of regional emergency medical services (EMS) and critical access hospitals (CAHs) [2]. In 2016, Nebraska's Department of Health and Human Services reported that there are 421 licensed emergency ambulance services, including 324 that provided basic services and are usually staffed with 1 or 2 emergency medical technicians (EMTs). Ninety-seven ambulance services were advanced life support ambulances [3]. Eighty-two percent of Nebraska's EMS providers are volunteers who serve sparsely populated geographically large areas and have very limited resources [3]. Although EMS providers receive training and certification to provide emergency care, those trainings may be outdated or may not have provided sufficient and/or individualized training to help meet the healthcare needs in rural communities.

The number of EMS providers in rural Nebraska has been declining. From December 2013 to June 2015, the number of Nebraska licensed EMS providers dropped by $13 \%$ from 8436 to 7367 . In the same period, the number of licensed EMS ambulance services dropped by 3\% from 426 to 414 [4]. The number of state-licensed EMS instructors also fell by $14 \%$ (311 to 266). Many EMS agencies have small numbers of personnel. For example, of 414 EMS agencies, 170 (41\%) have 10 or fewer licensed providers, and 35 (8\%) have 5 or fewer [4]. Staffing in rural CAHs is highly variable that some of these facilities are staffed by residency-trained emergency medicine practitioners, while others are staffed by family practitioners. These staffing issues result in significant variation in team coordination and effectiveness across CAHs in delivering emergency medical care [4].

For many EMS volunteers and emergency department (ED) staff serving in rural areas, it is very challenging to find close-by training opportunities that will allow them to stay up-to-date in their skills. Moreover, volunteers have the burden of added cost of travel to where training is provided. Training is especially critical since highly acute but low-frequency situations in rural areas make it difficult for providers to practice emergency clinical skills.

To help address these training needs, the Simulation in Motion-Nebraska (SIM-NE) program was funded to provide a mobile, state-of-the-art simulation-based training program to EMS providers who serve in rural areas of Nebraska. SIM-NE consists of four purpose-built trucks each of which has two simulation labs; one simulates an ambulance scene and the other simulates an emergency room. The trucks are equipped with a variety of clinical instruments, placebo-based medications with prescription labels (e.g., injectable, antihypertensive), and high-fidelity manikins that simulate a wide range of health issues resulting from chronic and communicable diseases, pregnancy, and external causes of injury. Several studies showed that using high-fidelity simulation is an effective teaching tool because it increases participants' learning satisfaction, self-confidence, performance, and self-efficacy [5-9]. Moreover, the use of such manikins and high-fidelity simulation provides educators with a more objective tool for participant evaluation and assessment of the training offered [9].

Each of the four SIM-NE program trucks will be housed in a different city (Norfolk, Scottsbluff, Kearney, and Lincoln) in four distinct rural regions (see Fig. 1). Each truck will then be able to travel into more rural areas in the designated region and offer on-site training to EMS volunteers and ED staff. The SIM-NE program offers a valuable opportunity for emergency medical professionals to perform hands-on, realistic clinical activities that fall under their scope of practice in an informed, encouraging, and supportive learning environment [10].

In addition to the potential benefit of the SIM-NE program in offering on-site training to address gaps in rural Nebraska, it is possible to offer customized training modules based on the needs of trainees. Thus, we undertook a systematic, state-wide survey and analysis of EMS providers to identify specific gaps in skills and knowledge. A combination of qualitative analysis of focus group findings and a survey of all EMS providers licensed in Nebraska was used.

\section{Methods}

This study followed a three-step process. First, we conducted focus groups in Nebraska at four distinct locations (Norfolk, Scottsbluff, Kearney, and Lincoln, see Fig. 1) to identify the thematic areas where the participants perceive there are gaps in their skills, knowledge, and abilities. Second, we developed a comprehensive survey tool and delivered to a large sample of healthcare professionals targeted by the SIM-NE program. Lastly, we analyzed the needs assessment survey; the results of which will inform the development of new and customized training modules in the future.

This study was deemed as a needs assessment/quality improvement by the Institutional Review Board at the University of Nebraska Medical Center (UNMC).

\section{Focus groups}

The four focus group locations were selected based on geographical catchment areas and to mirror the four towns where the trucks will be housed from their service areas. The research team conducted the focus group sessions between November and December of 2016. Table 1 represents the distribution of participants of the focus groups by location. Semi-structured 90-min-long focus group sessions 


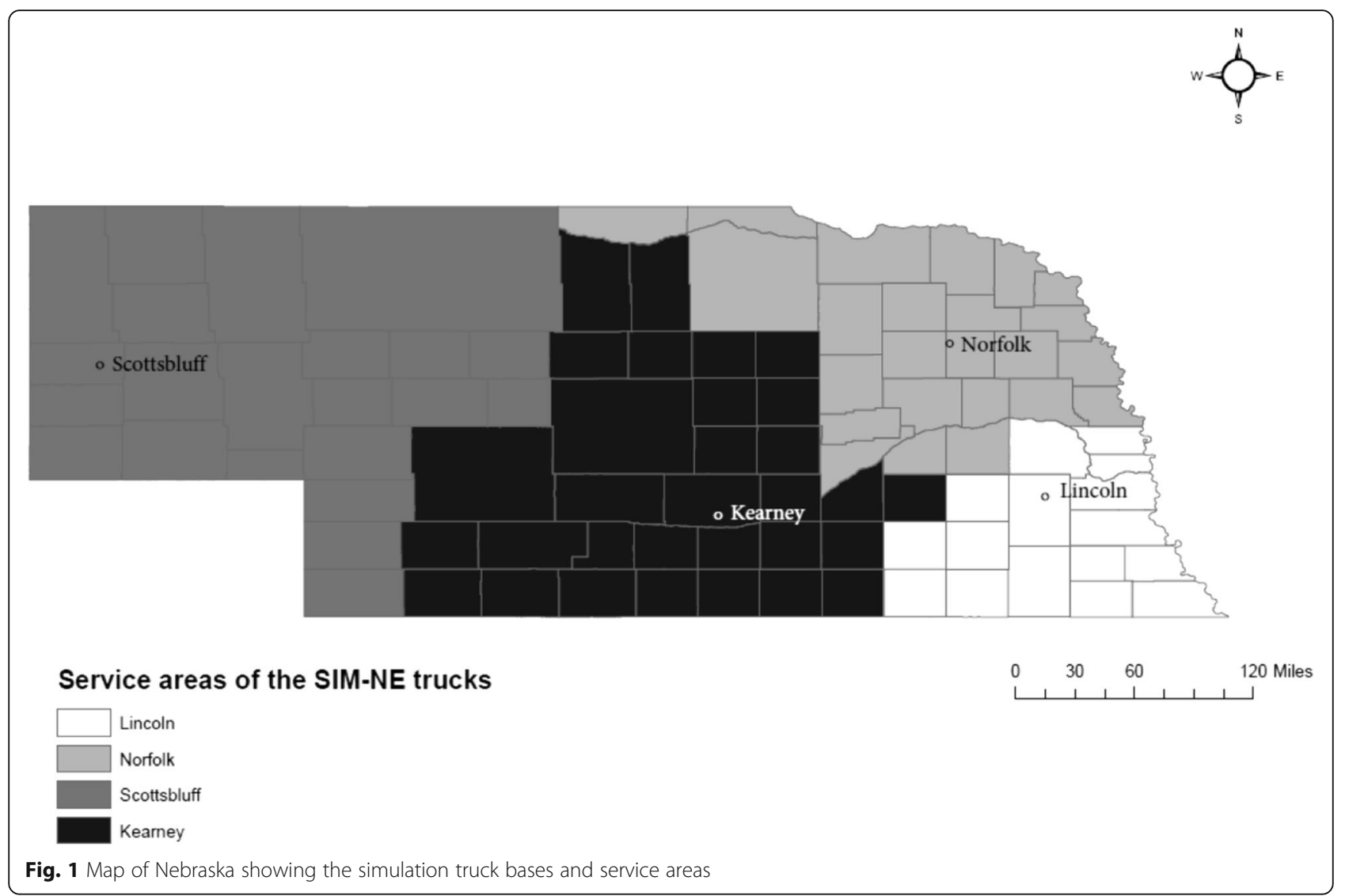

were conducted by a facilitator who facilitated the discussion with the following topics: (1) clinical skills with which you are less comfortable (or use infrequently) and would appreciate further training, (2) clinical skills for which you would like refresher training, and (3) non-clinical skills (e.g., patient report, teamwork, decision-making) for which you would like training (see Appendix). Using a collaborative consensus-building process, the facilitator guided the participants to cluster their responses in thematic groups. Through refining the data, it was possible to determine overarching areas that represent gaps in the participants' collective skills, knowledge, and abilities.

\section{Needs assessment survey}

The data collected during the focus groups identified 12 overarching thematic areas that were used to develop a

Table 1 Distribution of focus group participants by location

\begin{tabular}{llll}
\hline $\begin{array}{l}\text { Location in } \\
\text { Nebraska }\end{array}$ & $\begin{array}{l}\text { Number of } \\
\text { participants } \\
\text { working in ED }\end{array}$ & $\begin{array}{l}\text { Number of } \\
\text { participants } \\
\text { working for EMS }\end{array}$ & $\begin{array}{l}\text { Total number } \\
\text { of participants }\end{array}$ \\
\hline Lincoln & 7 & 1 & 8 \\
Norfolk & 5 & 0 & 5 \\
Kearney & 10 & 3 & 13 \\
Scottsbluff & 8 & 0 & 8 \\
\hline
\end{tabular}

survey questionnaire tool. The target population included physicians, physician assistants, advanced practice registered nurses (APRN), advanced EMTs, EMS instructors, EMTs, EMT-Intermediates, emergency medical responders, and paramedics. The Health Professionals Tracking Services (HPTS) at UNMC maintains data on the healthcare providers' license type, age, gender, and practice locations. The HPTS provided the mailing address of the above target providers. A paperbased survey was mailed to 7676 licensed health professionals. The survey collected education attainment and practice setting from respondents as well as training needs, based on the themes identified by the focus group sessions. The survey asked the respondents to rate their need for emergency training on a 5-point Likert scale ranging from "no need" to "very high" (1 to 5 points). Training needs were categorized into the following 12 thematic areas: cardiopulmonary events, diabetic management, mass casualty incident, maternal health and child delivery, patient assessment, pediatric and infant care, respiratory emergency, trauma, basic clinical skills, behavioral health, communication, and patient reporting between providers, teamwork, and decision-making. Qualitative data, from an open-ended question, were also collected to probe for other gaps beyond those listed in the survey. 
Quantitative data were analyzed using STATA software, version 14.0 (Stata Corporation, College Station, TX). Qualitative analysis, based on grounded theory, was performed by two independent coders to identify the common themes using MAXQDA software (Berlin, Germany) [11]. Grounded theory was used because it includes the identification and integration of categories or themes to derive meaning from collected qualitative data. The guidelines on how to identify categories and links or relationships between themes are provided as well as an explanatory framework to elucidate the study at hand [12].

\section{Results}

\section{Focus groups}

Table 1 represents the location distribution of participants who attended the focus group. Kearney had the highest attendance of 13 participants comprising both ED and EMS professionals while Norfolk had the lowest attendance of only 5 ED professionals. A total of 8 ED and EMS professionals attended the focus group session at Lincoln while participants at Scottsbluff included only 8 ED professionals.

Table 2 lists the thematic areas defined by the collaboration process. Each theme contains a list of clinical or non-clinical skills identified as a training need. All four locations identified similar challenges. Maternal health and child delivery was a common theme identified at all locations with participants requesting training for clinical skills like postpartum hemorrhage care, precipitous and regular delivery, shoulder dystocia, and neonatal resuscitation. Participants at all locations mentioned a need for refresher trainings for cardiovascular emergencies including stroke, cardiac arrest, acute myocardial infarction, and cardioversion. Similarly, participants from all locations unanimously requested retraining for respiratory emergencies, for example, intubation, respiratory arrest, anaphylaxis, and intraosseous needle insertion. Participants identified training needs for frequently encountered cases such as trauma of chemical exposure, electricity and fire, farming, neurology injury, and gunshots. Moreover, participants at all locations expressed a need for training to detect and treat behavioral health-related emergencies. Pediatric and infant care, including trauma and performing emergency procedures on pediatric patients, was also deemed as a training need at all four locations. All participants expressed a need to train themselves to help patients manage diabetes using the glucometer and insulin pump.

Besides the clinical skills, all participants emphasized the need for training on non-clinical skills. For example, training is needed to improve communication and efficient handoffs between providers during team transition.

\section{Needs assessment survey}

\section{Quantitative analysis}

Table 3 shows that the response rate to the survey was $18.1 \%$ (1390 of 7676 providers). The majority of the
Table 2 List of clinical and non-clinical skills the participants of focus group need further training in

\begin{tabular}{|c|c|}
\hline Themes & Types of skills \\
\hline Behavioral health & $\begin{array}{l}\text { Acute psychiatric conditions } \\
\text { Detoxification } \\
\text { Detection and treatment } \\
\text { for behavioral emergencies }\end{array}$ \\
\hline Cardiac care & $\begin{array}{l}\text { Acute myocardial infarction } \\
\text { Stroke } \\
\text { Cardioversion/pacing } \\
\text { Cardiac arrest management }\end{array}$ \\
\hline $\begin{array}{l}\text { Communication and handoffs between } \\
\text { providers }\end{array}$ & $\begin{array}{l}\text { Team transition } \\
\text { Scene dynamics }\end{array}$ \\
\hline Diabetes management & $\begin{array}{l}\text { Diabetic ketoacidosis } \\
\text { Insulin pump } \\
\text { Glucometer }\end{array}$ \\
\hline Maternal health and child delivery & $\begin{array}{l}\text { Postpartum hemorrhage } \\
\text { Delivery: precipitous/regular } \\
\text { Abruption } \\
\text { Shoulder dystocia } \\
\text { Neonatal resuscitation }\end{array}$ \\
\hline Pediatric and infant care & $\begin{array}{l}\text { Pediatric trauma } \\
\text { Emergency procedures }\end{array}$ \\
\hline Respiratory emergency & $\begin{array}{l}\text { Intubation } \\
\text { Respiratory arrest } \\
\text { Anaphylaxis } \\
\text { Needle decompression/ } \\
\text { chest tube } \\
\text { Intraosseous placement }\end{array}$ \\
\hline Teamwork and decision-making & $\begin{array}{l}\text { Continuation of care } \\
\text { Decision to transfer } \\
\text { (whole team) } \\
\text { Multi-victim trauma }\end{array}$ \\
\hline Trauma & $\begin{array}{l}\text { Burns from overexposure to } \\
\text { chemicals, electricity, and fire } \\
\text { Farming/ranching injuries } \\
\text { Neurotrauma } \\
\text { Hemorrhage gunshots }\end{array}$ \\
\hline
\end{tabular}

The themes are arranged in alphabetical order

respondents were male $(58.7 \%)$. The average age of all respondents was 50.5 years (SD 13.7). The results showed that $31.4 \%$ of the respondents had an associate's degree while $27.4 \%$ had a high school degree or general education diploma (GED). The majority of respondents $(80.5 \%)$ practiced in the setting of emergency medical services (EMS) while only $3.2 \%$ practice in the emergency department (ED) and $14.3 \%$ practiced in both settings. The results showed that $68.2 \%$ had only an EMT license while $2.0 \%$ had an EMT and an EMS instructor license. Also, 4.8\% were physicians and 3.5\% were physician assistants. A few of the advanced practice registered nurses (APRN) had a second license such as EMT and paramedics.

Surveys asked the participants to rate their training needs in identified categories on a Likert scale from 1 to 5 (1, no need; 2 , low; 3 , moderate; 4 , high; 5 , very high). Table 4 categorizes 1 and 2 as low need and 3, 4, and 5 as moderate to high need. The majority of respondents 
Table 3 Descriptive characteristics of respondents of the needs assessment survey

\begin{tabular}{|c|c|c|}
\hline Characteristics of respondents & $\begin{array}{l}\text { Number }(N= \\
1384)^{* * *}\end{array}$ & Percent \\
\hline \multicolumn{3}{|l|}{ Age in years } \\
\hline $20-35$ & 250 & 18.1 \\
\hline $36-45$ & 304 & 22.0 \\
\hline $46-65$ & 684 & 49.4 \\
\hline More than 65 & 146 & 10.5 \\
\hline \multicolumn{3}{|l|}{$\operatorname{Sex}^{*}$} \\
\hline Female & 569 & 41.1 \\
\hline Male & 812 & 58.7 \\
\hline Unidentified & 3 & 0.2 \\
\hline \multicolumn{3}{|l|}{ Education level ${ }^{* *}$} \\
\hline Less than high school & 3 & 0.2 \\
\hline High school/GED & 379 & 27.4 \\
\hline Associate's degree & 435 & 31.4 \\
\hline Bachelors & 325 & 23.5 \\
\hline Master's degree & 135 & 9.8 \\
\hline Doctorate & 88 & 6.4 \\
\hline No response & 19 & 1.4 \\
\hline \multicolumn{3}{|l|}{ Practice setting } \\
\hline Emergency department & 44 & 3.2 \\
\hline Emergency medical services & 1114 & 80.5 \\
\hline Practice in both & 198 & 14.3 \\
\hline No response & 28 & 2.0 \\
\hline \multicolumn{3}{|l|}{ License type } \\
\hline \multicolumn{3}{|l|}{ EMT/EMS } \\
\hline Advanced EMT only & 2 & 0.1 \\
\hline EMT only & 944 & 68.2 \\
\hline EMT-Intermediate only & 10 & 0.7 \\
\hline Emergency medical responder only & 74 & 5.3 \\
\hline EMT + EMS instructor & 27 & 2.0 \\
\hline EMT-Intermediate + EMS instructor & 1 & 0.1 \\
\hline EMS instructor + emergency medical responder & 1 & 0.0 \\
\hline \multicolumn{3}{|l|}{ Medical professionals } \\
\hline $\begin{array}{l}\text { Advanced practice registered nurse (APRN) } \\
\text { only }\end{array}$ & 24 & 1.7 \\
\hline Physician only & 66 & 4.8 \\
\hline Physician assistant (PA) only & 49 & 3.5 \\
\hline$P A+E M T$ & 2 & 0.1 \\
\hline APRN + EMT & 4 & 0.3 \\
\hline APRN + paramedic & 1 & 0.1 \\
\hline \multicolumn{3}{|l|}{ Paramedics } \\
\hline Paramedic only & 140 & 10.1 \\
\hline Paramedic + EMS instructor & 39 & 2.8 \\
\hline
\end{tabular}

*Gender information was provided by HPTS; gender information of three respondents showed unidentified in the HPTS database

${ }^{*}$ EEducation level and practice setting were collected from surveys. Few respondents did not answer these two questions

***Although we receieved 1390 surveys, there were 6 duplicates that were eliminated
(89.6\%) rated "mass casualty incident" as moderate to high need, and $88.0 \%$ and $87.7 \%$ respondents rated "pediatric and infant care" and "respiratory emergency" as moderate to high need, respectively. While most respondents $(84.4 \%)$ from Lincoln rated training of pediatric and infant care was moderately to highly needed, most respondents from Kearney (91.4\%), Norfolk (90.3\%), and Scottsbluff (90.3\%) rated training of respiratory emergency care as moderate to high need.

\section{Qualitative analysis}

We analyzed the responses obtained from the open-ended question "What other training do you think you need?" (Table 5). The results showed that $69 \%$ of the respondents did not indicate a need for any additional training. The nine key themes deemed necessary for training besides the ones proposed in the survey included (a) retraining of life support-related courses, (b) debriefing of protocols, (c) conducting rescue operations from fire- and water-based emergencies, (d) trauma, (e) substance use-related emergencies, (f) farming- and agriculture-related injuries, (g) administering medications and adverse drug reactions, (h) intubation and breathing difficulties, and (i) training tailored for rural areas. Based on the frequency of the responses, we ranked these themes and selected supporting quotes as shown in Table 5.

There were 133 respondents who mentioned a need for a refresher of Emergency Vehicle Operator Course (EVOC), Advanced Trauma Life Support (ATLS), Pediatric Advanced Life Support (PALS), and cardiopulmonary resuscitation (CPR). Around 14\% of respondents expressed a need for education related to paperwork, protocols from health agencies, and methods to keep records. Fire- and water-related rescue operations were common across the state, and $12 \%$ of respondents mentioned a need to procure training for such emergencies. Fifty-four respondents indicated a need for a refresher training on stabilizing patients involved in trauma while 34 respondents requested education on treating patients who overdosed illegal drug and narcotics.

Thirty-one respondents requested training on caring for patients suffering from farming-related injuries and agriculture-related incidents. Administering medications such as naloxone, and helping patients combat adverse drug reactions, also requires hands-on training which respondents (28) believe can be provided by simulation-based education.

\section{Discussion}

In this study, we undertook a comprehensive review of current training needs in rural Nebraska, USA, utilizing both in-depth focus group discussions and a broad-based quantitative survey. Results from this needs assessment identified key opportunities to improve the knowledge and skills among the workforce. These areas included treatment of cardiopulmonary conditions, diabetic 
Table 4 Frequency of training needs by skills and mean training needs rated by area

\begin{tabular}{|c|c|c|c|c|c|}
\hline \multirow[t]{2}{*}{ Skills } & \multirow{2}{*}{$\begin{array}{l}\text { Moderate } \\
\text { to high } \\
\text { need* }(\%)\end{array}$} & \multicolumn{4}{|c|}{ Moderate to high training need by area (\%) } \\
\hline & & Lincoln & Kearney & Norfolk & Scottsbluff \\
\hline Basic clinical skills & 61.0 & 52.0 & 65.3 & 66.6 & 64.6 \\
\hline Behavioral health & 70.5 & 62.0 & 74.7 & 71.7 & 86.6 \\
\hline Cardiopulmonary & 85.3 & 82.3 & 85.5 & 87.3 & 90.0 \\
\hline $\begin{array}{l}\text { Communication and handoffs } \\
\text { between providers }\end{array}$ & 60.0 & 55.0 & 61.7 & 64.0 & 64.6 \\
\hline Diabetic management & 72.0 & 63.2 & 78.1 & 75.5 & 74.3 \\
\hline Mass casualty incident & 89.6 & 87.6 & 87.9 & 93.5 & 92.0 \\
\hline Maternal health and child delivery & 74.9 & 76.6 & 72.8 & 73.3 & 78.8 \\
\hline Patient assessment & 70.5 & 64.4 & 74.2 & 75.1 & 69.9 \\
\hline Pediatric and infant care & 88.0 & 84.4 & 90.6 & 89.9 & 88.5 \\
\hline Respiratory emergency & 87.7 & 82.1 & 91.4 & 90.3 & 90.3 \\
\hline Teamwork and decision-making & 65.0 & 58.5 & 70.4 & 68.2 & 66.4 \\
\hline Trauma & 87.5 & 83.3 & 90.3 & 90.0 & 88.4 \\
\hline
\end{tabular}

Surveys asked the participants to rate the training needs on a scale of 1 to 5 . Training needs of 1 and 2 are categorized as low need and 3,4 , and 5 as moderate to high need

*The sum of individual counts may not add up to the total number of respondents because of missing information for certain variables

management, mass casualty incidents, maternal health and child delivery, patient assessment, pediatric and infant care, and respiratory emergency care. Gaps in non-clinical skills were related to crisis management such as maintaining effective communication and teamwork among the EMS and ED providers. These findings will be used to develop curricula for an innovative mobile simulation program to address the rural community needs.

The provision of emergency services in rural areas involves unique challenges compared to urban settings. Such challenges include long travel distances, difficulties in assembling qualified teams, and agricultural-related injuries. Consistent with the study by Fleischman, responses from our study highlighted that ED and EMS personnel have few prior training sessions, infrequent incidences to apply clinical skills, and a generally low level of comfort in addressing emergencies [13]. Also, the prior literature suggests that providers in rural hospitals experienced inferior quality of education, lower number of practitioners, and limited financial resources compared to urban providers $[2,13]$. Our findings present a clear need for a regular and updated training program tailored to the needs of rural EMS providers.

Infants and children account for approximately 4 to $13 \%$ of medical emergencies in rural areas [13, 14]. However, the standards mandated regarding the number of hours of pediatric training are inconsistent across different organizations such as the National Standard Curriculum, the National EMS Education Standard, and the National Registry of Emergency Medical Technicians [13]. This may explain the discomfort and limited experience with pediatric and infant care reported by our participants. The Institute of Medicine (IOM) reports that having a low volume of pediatric patients results in lower levels of preparedness for pediatric ED patients by rural emergency medical providers [15]. Previous literature has established the importance of conducting medical training focused on pediatric and infant emergency care $[13,16]$. In fact, the SIM-NE program uses highly realistic manikins of newborns and infant children and thus will help address the concerns of our study participants regarding training in life-saving and complicated clinical procedures for pediatric patients. Such situations include obstetric hemorrhage and other delivery complications, neonatal resuscitation, intubation, and drowning. These concerns are likely to be shared by EMS providers in other rural communities.

Participants of our focus groups and respondents to the survey generally mentioned their lack of practical skills while treating trauma patients. The participants gave examples of multiple trauma activities for which they felt ill-equipped; such cases include burns (from chemical, electrical, and fire), head injuries, wounds from gunshots, amputations, profuse bleeding hemorrhage, and splinting. While an advanced trauma life support (ATLS) course typically uses simulated trauma scenarios, these courses are only available in post-graduate educational programs $[17,18]$. However, a large proportion of EMS providers practicing in Nebraska usually does not have postgraduate degrees. Thus, training programs are needed to address this gap.

Almost $90 \%$ of respondents reported a need for further training in mass casualty incidents (MCI). Prior research suggests that simulation-based training for $\mathrm{MCI}$ can 


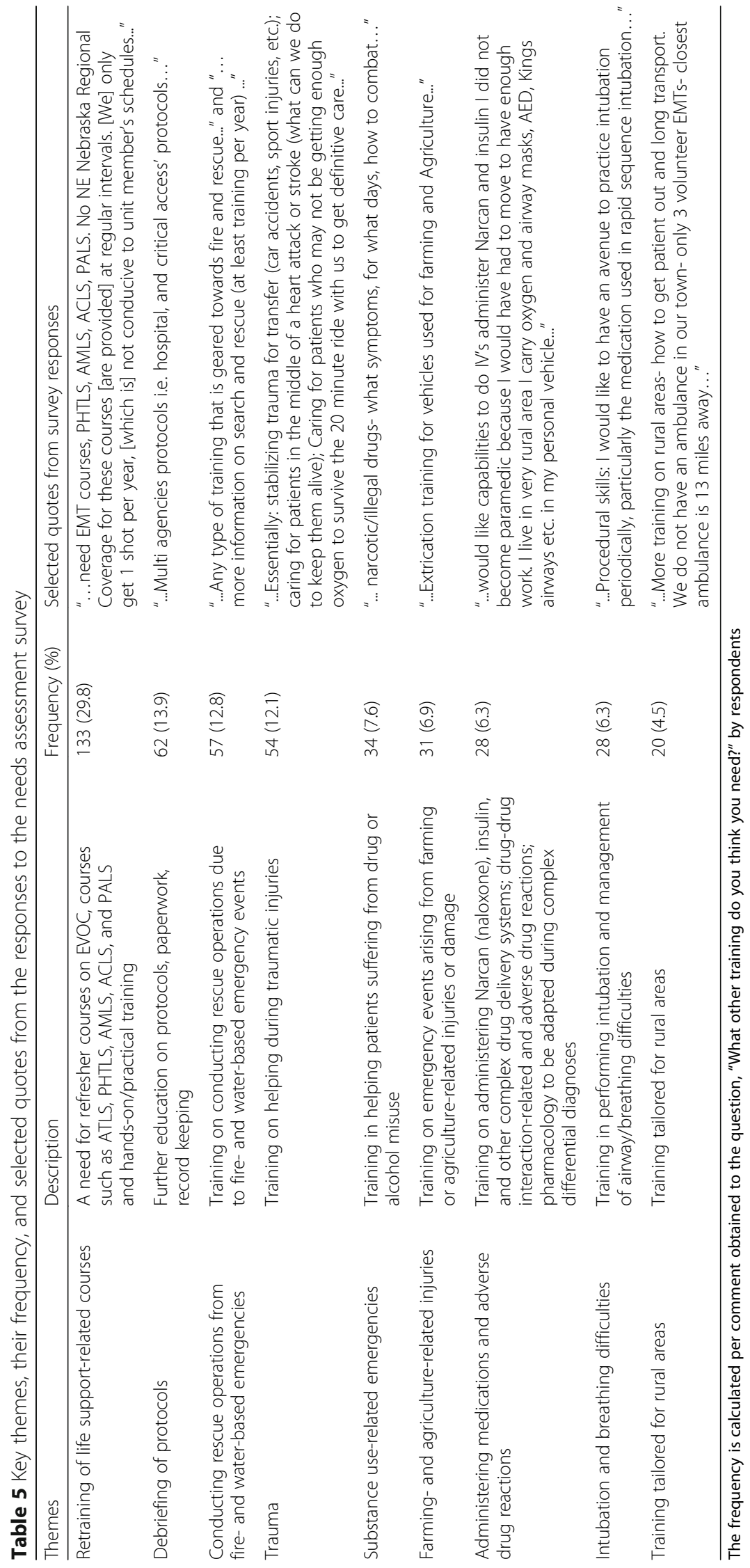


effectively increase critical thinking capacity, functionality within the healthcare team, and ability to learn from mistakes [19]. Effective handling of MCI requires a systematic evaluation of emergency preparedness and disaster awareness. Unfortunately, we found that rural EMS providers have few opportunities to develop skills in MCI within realistic scenarios. Our findings call for hands-on training programs to address readiness for manmade or natural disasters.

Our findings have informed curriculum development for the SIM-NE trainings that will specifically address the skills and knowledge gaps identified by our focus groups and survey results. For example, a considerable proportion of responses emphasized the importance of glucometers and insulin pumps to aid emergency treatment of diabetes patients. To address this concern, the SIM-NE truck has the capability to train EMS providers in treating acute cases of uncontrolled diabetes. By grounding training programs to the needs assessment of rural communities, simulation-based programs can provide training that is responsive to these needs.

Our findings also identified several non-clinical areas of concern in emergency services, such as teamwork. Although successful team leadership as well as safe and effective delivery of prehospital care is required as part of the National EMS Education Standards, the components of effective teamwork have not been clearly defined [20, 21]. Consistent with previous studies [20, 22, 23], the important characteristics of effective teamwork that the respondents rated as "high need" for training include situational awareness, task management, coordinating dissimilar information, decision-making, and communication. Having both a simulated ED and ambulance unit within the SIM-NE truck, it is possible to evaluate and enhance teamwork for both EMT and ED staff. Other important issues impacting rural healthcare identified through our focus group discussions are significantly limited resources among rural EMS providers, small emergency care teams, and insufficient financial support for hands-on training.

It is very important to realize that our study findings are as beneficial to other rural communities and sparsely populated areas in the USA or even in the world. Such challenges facing ED and EMS providers are many times similar by the virtue of travel distances, limited resources, and low frequency of emergent cases.

This study has limitations. Organizing the focus groups included challenges such as low rates of participation by ED and EMS professionals. The unequal representation of ED and EMS providers and the small representative sample of the focus groups might have resulted in missing some of the training needs. Moreover, ED and EMS providers although react to similar emergency cases, each has a different set of required skills and competencies. Having a more representation of each group would have allowed us to capture more of the nuances that exist. Nonetheless, the focus group process was meant to provide the foundation for survey development.

The survey was not checked for validity and reliability or piloting. It might be argued that individuals might interpret questions in different ways. Nonetheless, the research team was ensured that the survey questions were simple and straightforward to minimize or even eliminate any variation in interpretation. Moreover, the intent of the study was to identify those training gaps and needs that would allow the SIM-NE program to better address these gaps.

Although we mailed the survey to 7676 licensed health professionals, we had a low response rate of $18 \%$. This might be a result of the fact that the majority of the EMS providers are volunteers and responding to surveys might not be top-of-mind. One can always argue that it might not be a representative sample or that it might suffer from selection bias. Nonetheless, we received 1390 responses which are a sizable cohort for our study and provided a rich dataset for analysis.

\section{Conclusions}

Few prior studies have undertaken a needs assessment of emergency services providers in predominantly rural states. In Nebraska, many EMT providers are volunteers and have limited access to resources, experience in applications of skills, and training opportunities to maintain or improve their clinical and non-clinical skills. Similarly, many rural ED staff may not receive many opportunities to address complex or challenging cases requiring emergent care. The inferences from focus group discussions and survey highlight a clear need for clinical and non-clinical training to ensure the effectiveness of the emergency services workforce. The findings of our study are not just limited to rural Nebraska but might also be applicable to other rural areas in the USA as well as the world. These results provided the basis to develop customized training curricula for EMT and ED staff in rural areas delivered through an on-site state-of-the-art mobile simulation-based program. Such method of delivery might be a model for colleges and other training programs to build capacity and be responsive to ongoing and unique needs of the healthcare workforce in rural communities.

\section{Appendix}

\section{Guide to facilitate focus group discussion}

1. Make a list of clinical skills with which you are less comfortable (or use infrequently) and would appreciate further training

2. Make a list of clinical skills for which you would like refresher training

3. Make a list of soft skills (i.e., patient report, teamwork, decision-making) for which you would like training 


\section{Abbreviations}

AMLS: Advanced Medical Life Support; APRN: Advanced practice registered nurse; ATLS : Advanced Trauma Life Support; CAH: Critical access hospital; CPR: Cardiopulmonary resuscitation; ED: Emergency department;

EMS: Emergency medical services; EMTs: Emergency medical technicians; EVOC: Emergency Vehicle Operator Course; GED: General education diploma; HPTS: Health Professionals Tracking Services; IOM: Institute of Medicine; MCl: Mass casualty incidents; PALS: Pediatric Advanced Life Support; PC: Pediatric care; PHTLS: Prehospital Trauma Life Support; SIMNE: Simulation in Motion-Nebraska; UNMC: University of Nebraska Medical Center

\section{Acknowledgements}

The authors would like to acknowledge Marlene Deras, Director of Health Professions Tracking Service, for the help and logistical support of survey administration

\section{Funding}

This study was supported by the Leona M. and Harry B. Helmsley Charitable Trust Grant \#2016PG-RHC044.

\section{Availability of data and materials}

The datasets generated and/or analyzed during the current study are not publicly available since they were collected for this particular project but are available from the corresponding author on reasonable request.

\section{Authors' contributions}

NKW contributed to the conception, design, acquisition, and interpretation of data. RW and YY contributed to the data acquisition, data collection and analysis, and drafting of the manuscript. FW and SM contributed to the design and interpretation of data and revision of the intellectual content. BM contributed to the conception and design of the survey and data acquisition. JA contributed to the conception and design of data acquisition. PP contributed to the conception of data acquisition and revision of the intellectual content. All authors read and approved the final manuscript.

\section{Ethics approval and consent to participate}

This study was deemed as a needs assessment/quality improvement by the Institutional Review Board at the University of Nebraska Medical Center.

\section{Consent for publication}

Not applicable.

\section{Competing interests}

The authors declare that they have no competing interests.

\section{Publisher's Note}

Springer Nature remains neutral with regard to jurisdictional claims in published maps and institutional affiliations.

\section{Author details}

'Department of Health Services Research and Administration, College of Public Health, University of Nebraska Medical Center, 984350 Nebraska Medical Center, Omaha, NE 68198-4350, USA. ²Department of Epidemiology, University of Nebraska Medical Center, Omaha, NE 68198, USA. ${ }^{3}$ Department of Family Medicine, University of Nebraska Medical Center, Omaha, NE 68198 , USA.

Received: 24 July 2018 Accepted: 30 October 2018

Published online: 23 November 2018

\section{References}

1. U.S. Department of Health and Human Services, Health Resources and Services Administration, Rockville, Maryland 2014. Shortage Areas. 2014. https://data.hrsa.gov/tools/shortage-area/hpsa-find. Accessed 25 July 2017.

2. Busko J. Rural EMS. In: Emergency medical services: clinical practice and systems oversight. Dubuque: Kendall-Hunt; 2008. p. 218-28.

3. Nebraska Board of Emergency Medical Services. 5 year report to the legislature 2016. Lincoln, NE: Nebraska Department of Health and Human Services. 2016
4. Ricketts P, Hurst G, Philips C. Nebraska FY 2015 Preventive Health and Health Services Block Grant: work plan. Lincoln, NE: Nebraska Department of Health and Human Services. 2015.

5. Mclaughlin SA, Bond W, Promes S, Spillane L. The status of human simulation training in emergency medicine residency programs. Simul Healthc 2006;1(January):18-21.

6. Okuda Y, Bond W, Bonfante G, Mclaughlin S, Spillane L, Wang E, Vozenilek J, Gordon JA. National growth in simulation training within emergency medicine residency programs, 2003-2008. Acad Emerg Med. 2008;15:1113-6.

7. Grant T, Mcneil MA. Absolute and relative value of patient simulator features as perceived by medical undergraduates. Simul Healthc. 2008;3(3):133-7.

8. Nguyen HB, Daniel-Underwood L, Van Ginkel C, Wong M, Lee D, Lucas AS, Palaganas J, Banta D, Denmark TK, Clem K. An educational course including medical simulation for early goal-directed therapy and the severe sepsis resuscitation bundle: an evaluation for medical student training. Resuscitation. 2009:80:674-9.

9. Ten Eyck RP. Simulation in emergency medicine training. Pediatr Emerg Care. 2011;27(4):333-41.

10. Gordon J. High fidelity patient simulation: a revolution in medical education. In: Dunn WF, editor. Simulators in critical care and beyond. Des Plaines: Soc Crit Care Med; 2004. p. 3-6.

11. Berends $L$, Johnston J, Berends $L$, Johnston J. Using multiple coders to enhance qualitative analysis: the case of interviews with consumers of drug treatment. Addict Res Theory. 2005;13(4):373-81.

12. Willig C. Introducing qualitative research in psychology. Berkshire, England: Open University Press. 2013.

13. Fleischman RJ, Yarris LM, Curry MT. Pediatric educational needs assessment for urban and rural emergency medical technicians. Pediatr Emerg Care. 2011;27(12):1130-5.

14. Shah MN, Cushman JT, Davis CO, Bazarian JJ, Auinger P, Friedman B. The epidemiology of emergency medical services use by children: an analysis of the National Hospital Ambulatory Medical Care Survey. Prehospital Emerg Care. 2008;12(3):269-76.

15. Institute of Medicine. Emergency care for children: growing pains. Washington: The National Academies Press; 2007. https://doi.org/10.17226/11655.

16. Glaeser PW, Linzer J, Tunik MG, Henderson DP, Ball J. Survey of nationally registered emergency medical services providers: pediatric education. Ann Emerg Med. 2000;36(1):33-8.

17. Buskye J. The role of simulation in certification. Surg Clin North Am. 2010; 90(3):619-21.

18. Borggreve AS, Meijer JMR, Schreuder HWR, Ten Cate O. Simulation-based trauma education for medical students: a review of literature. Med Teach. 2017;39(6):631-8.

19. Shannon CC. Using a simulated mass casualty incident to teach response readiness: a case study. J Nurs Educ. 2015;54(4):215-9.

20. Crowe RP, Wagoner RL, Rodriguez SA, Bentley MA, Page D. Defining components of team leadership and membership in prehospital emergency medical services. Prehosp Emerg Care. 2017;21(5):645-51.

21. U.S. Department of Transportation. National Emergency Medical Services Education Standards: Advanced Emergency Medical Technician Instructional Guidelines. CreateSpace Independent Publishing Platform. 2009.

22. Baker DP, Gustafson S, Beaubien JM, Salas E, Barach P. Medical team training programs in health care. In: Henriksen K, Battles JB, Marks ES, Lewin DI, editors. Advances in patient safety: from research to implementation (volume 4: programs, tools, and products). Rockville: Agency for Healthcare Research and Quality (US). 2005. Adv Patient Saf. p. 253-68. https://www. ncbi.n/m.nih.gov/books/NBK20580/. Accessed 25 July 2017.

23. Clay-Williams R, Braithwaite J. Determination of health-care teamwork training competencies: a Delphi study. Int Qual Heal Care. 2009;21(6):433-40. 